\title{
O papel das Instituições Internacionais na promoção do Espaço Público brasileiro: uma análise a partir do pensamento Arendtiano*
}

\author{
The role of international institutions in \\ promoting Brazilian Public Space: an analysis \\ from Arendt thought
}

\section{Resumo}

Em 2001, a Comissão Interamericana de Direitos Humanos condenou o Estado Brasileiro por omissão em um caso específico de violência doméstica. A sentença condenatória constitui-se em marco na história do país ao determinar não apenas a reparação da vítima, mas também a criação de lei específica que disciplinasse a matéria. No plano doméstico, a decisão desencadeou um rico debate público, com a participação de diversos setores e atores da sociedade brasileira. O resultado foi a elaboração de políticas públicas com recorte de gênero, com o objetivo de tornar a mulher brasileira não só imune da violência, mas partícipe da vida pública, portando das mesmas prerrogativas que os homens. Dessa forma, o objetivo deste trabalho é discutir em que medida um organismo internacional, pautado na universalidade dos direitos humanos, contribui para a promoção do espaço público nacional, direcionando crítica ao pensamento arendtiano acerca do processo de abertura desses espaços; à sua elaboração de espaço público versus espaço privado, que pode contribuir para a inserção assimétrica dos indivíduos no espaço público; e à sua concepção do termo right to have rights.

Palavras-chave: Comissão Interamericana de Direitos Humanos. Hannah Arendt. Violência doméstica. Direitos humanos. Espaço público x espaço privado.

\begin{abstract}
In 2001, the Inter-American Commission on Human Rights condemned the Brazilian state by omission on a specific case of domestic violence. The condemnatory sentence constituted a landmark in the country's history by determining not just the victim 's reparation, but also the creation of a specific law that disciplined the subject. In the domestic plan, the decision triggered a rich public debate, including the participation of different sectors and actors of Brazilian society. The result was the elaboration of gender public policies aiming at Brazilian woman not just become immune from violence but also participant of public life, having the same rights as men. In this way, the aim of this paper is to discuss in which extend an international organism underpinned in the universality of human rights contributes to the formation of the national public space, directing therefore a critique to the Arendt thought about the opening process of these spaces, to her elaboration of public space vs private space, which can contribute to the asymmetric insertion of the individuals in the public sphere, and to her conception of right to have rights.
\end{abstract}

Keywords: Inter-American Commission on Human Rights. Hannah Arendt.

Domestic violence. Human rights. public space x private space.

* Recebido em 13/02/2014.

Aprovado em 9/04/2014.

${ }^{1}$ Doutoranda em Política Internacional e Resolução de Conflitos na Universidade de Coimbra. E-mail: amanda.sanches2@gmail.com; 


\section{Introdução}

A temática dos direitos humanos, em todas as suas dimensões, tornou-se pauta permanente no foro das relações internacionais e no âmbito interno. Muitos foram os eventos que contribuíram decisivamente, ao longo dos séculos, para discussões atuais sobre o tema, bem como os mecanismos necessários para implementar esses direitos. No fundamento deste debate está o papel do Estado como garantidor imprescindível ou não dos direitos intrínsecos a cada indivíduo, discutindo-se até que ponto este agente deve avançar da esfera pública à esfera privada para assegurar este processo.

Nos escritos arendtianos, por exemplo, o tema dos direitos humanos apresenta-se como um dos pontos centrais da sua discussão. A sua construção fundamenta-se na crítica à acepção atual que condiciona a garantia desses direitos a uma instituição e que assume a pertença do indivíduo a uma comunidade política. A autora busca enraizar os direitos humanos em um princípio que seja comum à condição humana, ou seja, a possibilidade de agir em um dado espaço público. Dessa forma, os direitos humanos na concepção arendtiana materializam-se na ação e no discurso do indivíduo, na capacidade de se comunicar e formar opinião (PAREKH, 2004, p. 45), o que cunha por right to have rights. Por sua vez, a ação é concebida por Arendt como uma atividade humana que reconhece o "Outro" enquanto igual, diferentemente do labor e do trabalho, encontrando no espaço público, por conseguinte, o local propício para o seu desenrolar (AVERITZER, 2006, p. 153-154).

A partir do entendimento do right to have rights, que se inicia na crítica aos direitos humanos, nos termos atuais em que se fundamentam, e que se finaliza na distinção entre espaço público e espaço privado, este trabalho propõe-se a evidenciar as falhas neste argumento, apresentando as seguintes considerações. Primeiro, a taxação por uma instituição internacional do que sejam os direitos humanos, ao contrário do que pensa Arendt, pode ir ao encontro do princípio fundamental proposto por si, uma vez que contribui para a promoção desse espaço em situações que o Estado falha ao prover tal fim, não adotando um indivíduo como pertencente a um grupo político, mas munindo-o de elementos que o tornem partícipe. Segundo, a formulação de espaço público sustenta-se na sua diferenciação do privado. Entretanto, essa caracterização pode não contribuir ou, em alguns casos, exacerbar desigualdades existentes em dada comunidade política, limitando, assim, a garantia dos direitos humanos nos termos arendtianos, ou seja, a participação livre dos indivíduos no espaço público, o sentimento de pertença a uma dada comunidade.

Dessa forma, pretende-se demonstrar que o entendimento do right to have rights, consubstanciado na ação do indivíduo no espaço público, à sua maneira, também não é uma solução plausível para assegurar a todos os direitos humanos. Por outro lado, a atuação dos organismos internacionais, pautada na universalidade dos direitos, pode contribuir para a abertura do espaço público, ao enfrentar questões importantes que, quando presentes, prejudicam a igualdade no acesso ao espaço público idealizado por Arendt.

Buscando cumprir a proposta deste trabalho, utiliza-se como estudo de caso a decisão da Comissão Interamericana de Direitos Humanos que condena o Estado brasileiro à reparação de vítima de violência doméstica $\mathrm{e}$ à criação de uma lei específica para o tratamento da matéria. Essa sentença ilustra como uma instituição internacional pode contribuir para a promoção do espaço público ao se analisar a repercussão dessa decisão na sociedade brasileira, trazendo para o foro de discussão a subalternidade da mulher e o compromisso com a elaboração de políticas públicas para a reversão deste quadro.

$\mathrm{O}$ artigo divide-se em duas seções. Inicialmente, discute-se a temática dos direitos humanos à luz do pensamento arendtiano, evidenciando nesta discussão como se articulam os conceitos de espaço público, espaço privado e ação. Posteriormente, aplica-se este entendimento ao estudo de caso escolhido, com o intuito de assinalar as falhas neste argumento.

\section{Direitos Humanos: entre o espaço público e as instituições}

Em As Origens do Totalitarismo, Hannah Arendt atribui uma especial atenção à temática dos direitos humanos. Finda a construção teórica dos elementos que estiveram presentes e que convergiram para a ascensão do totalitarismo, a autora dedica-se à questão das minorias e dos desprovidos de direitos, buscando identificar as condições que tornaram esse evento possível, as quais permanecem ainda hoje, e a relação entre direito e política (PAREKH, 2004, p. 41).

A partir dessa observação, Arendt critica e questiona os preceitos que fundamentam os direitos humanos, 
argüindo que a barbárie dispensada contra esses grupos foi possível apenas em virtude da 1) fragilidade do Estado em assegurar esses direitos e também a 2) adoção do homem como já pertencente a alguma comunidade política.

A primeira assertiva traduz-se em uma dicotomia. Ao mesmo tempo em que o Estado/instituição proclama os direitos humanos, são também esses mesmos atores que se responsabilizam por assegurá-los e promovê-los No entanto, o paradoxo reside quando o principal agente responsável pela observância dos direitos humanos, no caso o Estado, além de não cumprir o seu dever, ainda atua no sentido contrário, excluindo determinados grupos das suas leis. Nesse sentido, a vontade e os interesses do Estado/instituição conflitam com os direitos dos seus cidadãos de tal forma que na composição das forças aquele tende a se sobrepor ao último, evidenciando uma tensão entre direitos humanos e estrutura (PAREKH, 2004, p. 41). O Estado pode facilmente tornar-se um instrumento da nação e não um protetor do indivíduo (LANG, 2005), se se esquece que os direitos do homem fazem parte da condição humana.

Concernente ao segundo ponto, a elaboração desses direitos não apenas evoca a necessidade de torná-los universal, mas adota como verdadeiro a inserção das pessoas nas comunidades políticas. Ademais, Arendt entende essa formulação como demasiado abstrata (COTTER, 2008, p. 100) e defende, ao contrário, a adoção de um princípio que seja inerente à condição humana, a qualquer tempo e espaço, para guiar os direitos humanos. Dessa forma, lança-se do termo right to have rights para referir-se a esse princípio, o qual compreende a ação como o instrumento que liberta o indivíduo, afastando-os da possibilidade de existência sem direito (OMAN, 2010, p. 279).

A ação é apresentada por Arendt na sua obra $A$ Condição Humana e juntamente com o trabalho e o labor, compreende o que a autora cunha por vita activa, ou seja, atividades que correspondem à vida humana na Terra (ARENDT, 2001, p. 19). No entanto, diferentemente dos outros dois elementos, a ação é "a única actividade que se exerce directamente entre os homens sem a mediação das coisas ou da matéria, corresponde à condição humana da pluralidade [...]", condição de toda a vida política (ARENDT, 2001, p. 20).

Arendt defende que o indivíduo integra o mundo humano por meio das palavras, da ação e do discurso, "[...] modos pelos quais os seres humanos se mani- festam uns aos outros, não como meros objetos físicos, mas enquanto homens" (ARENDT, 2001, p. 225). Acrescenta, por conseguinte, que "a vida sem discurso e sem acção [...] está literalmente morta para o mundo [...]" (ARENDT, p. 2001, p. 225). Não obstante, os elementos da vida activa têm em si imbuídos a esperança do recomeço, do novo, daqueles que renovam o espaço político, onde os homens se revelam sujeitos e singulares e, desta forma, constroem o plural. Rejeitar esse processo é o erro básico de todo o materialismo político (ARENDT, 2001, p. 232-232), porque

A rigor, a esfera dos negócios humanos consiste na teia de relações humanas que existe onde quer que os homens vivam juntos. A revelação da identidade através do discurso e o estabelecimento de um novo início através da acção incidem sempre sobre uma teia já existente, e nela imprimem as suas conseqüências imediatas. Juntos, iniciam um novo processo, que mais tarde emerge como a história singular da vida do recém-chegado, que afecta de modo singular a história da vida de todos aqueles com quem ele entra em contato.

No pensamento arendtiano, a ação é uma atividade política por excelência, porque os homens reunidos sob a ação e o discurso criam a esfera da aparência ou a esfera pública, a qual, por sua vez, existe antes mesmo de qualquer constituição formal ou forma de governo. A sua manutenção decorre da capacidade de atuação conjunta dos indivíduos singulares, entendido por Arendt, como o ato que gera o poder, de tal forma que a renúncia à convivência pressupõe a renúncia ao poder, tornando impotente o indivíduo (ARENDT, 2001, p. 250-253). Ademais, o poder que se cria no seio do espaço público, de cidadãos livres é um mecanismo capaz de resistir e de transformar pacificamente, o que torna Arendt como defensora da política não violenta (OWENS, 2007).

Ainda assim, é no âmbito da comunidade arendtiana que emerge também o direito. E considerando-o um artífice do homem, pode embasar e dar origem às concepções e modelos diferentes de governo, os quais limitam a ação do cidadão. Ou seja, é o espaço público que origina a lei, as estruturas e o governo. No entanto, como salienta Arendt, com exceção da tirania, esses regimes, ainda que regulem a liberdade do homem, promovem espaços que garantem a "liberdade de ação que efectivamente põe em movimento o corpo constituído pelos cidadãos" (ARENDT, 1978, p. 216). Esse movimento, por conseguinte, constrói comunidades singulares, símbolos de leis, costumes, memórias, hábitos (idem), de tal forma que não pode ser validada 
além dos limites fronteiriços, por diferirem dos anseios de outros povos (ARENDT, 2004, p. 166).

Entretanto, a atuação livre dos indivíduos na esfera das aparências tem sustentabilidade também na esfera privada, que provê os meios necessários para tal fim, fixando uma relação de contraste com o espaço público (FRAZER, 2009, p. 207). Enquanto estes pressupõem a publicização do relevante, à esfera privada restringe-se tudo o que se considera irrelevante (ARENDT, 2001, p. 67). Outrossim, é este espaço que resguarda a atuação do homem na esfera pública ao voltar-se para à propriedade, ao labor e trabalho, de modo que liberta os agentes da ação para se dedicar à esfera pública.

Nesse contexto, a fundamentação que Hannah Arendt busca para sustentar a sua concepção de direitos humanos diverge dos pressupostos atuais que os consubstanciam. Arendt valoriza o local para atingir esse direito, sem, no entanto, vinculá-lo a nenhum governo, tendo em vista que o espaço público se materializa tão somente a partir da convivência humana. É o que concebe por right to have rights contrariamente à interpretação que atribuiu aos direitos humanos, considerando-os, diante desses paradoxos, apenas direitos civis que são implementados ou não a depender de cada comunidade política (OMAN, 2010, p. 281).

No entanto, a proposta de Arendt para solucionar este problema, não aponta caminhos concretos, não obstante ser um uma solução que se direciona à produção dos mesmos efeitos a que a autora combate. Como mencionando anteriormente, se essas instituições reiteradamente falham na implementação desses direitos (exemplo o que ocorreu com os judeus), evidenciando na prática que a universalização e a inalienabilidade, supostamente inerentes àquele conceito, são um engodo à medida que se condiciona aos interesses da soberania estatal (COTTER, 2008, p. 100), então, quais as conseqüências decorrentes da tentativa de atribuir direito a partir do local em contraposição ao nacional ou universal?

$\mathrm{Na}$ percepção arendtiana, o direito a ter direitos nasce da participação do indivíduo no espaço público, momento em que se coloca enquanto homem singular através do discurso e da ação. Mas se a possibilidade de atuar nessa esfera não vem precedida do princípio da igualdade e da certificação de que todos os indivíduos comungam do mesmo capital social, político e material, por conseguinte, não só a convivência além dos limites privados será restrita, como também toda a estrutura dela originada será vi- ciosa. Em outras palavras, as instituições que se encontram no centro da crítica arendtiana, por falharem na garantia dos direitos humanos, herdam os vícios que decorrem da composição desigual do espaço público.

Se o Estado, como representante máximo dessa estrutura, apresenta elementos que podem comprometer a esfera pública, considerando a sua tendência em "reificar estruturas de governança em rígidas hierarquias com elites que removem os indivíduos da potencial esfera da ação política 2" (WILLIAMS; LANG, 2005, p. 20), por outro lado, a própria abertura do espaço público pode condicionar a fragilidade do funcionamento das estruturas, tornando-se um círculo vicioso.

Ainda assim, quanto à crítica arendtiana destinada aos direitos humanos, somado ao problema dos interesses soberanos e das estruturas frágeis, tem-se a universalização desses direitos, os quais, por assumirem uma lógica top down, podem confrontar com a cultura e as necessidades locais, constituindo-se em óbice ao fortalecimento do Estado-nação enquanto reflexo da atividade política comunitária e também como garantidor dos direitos individuais (LEE, 2011, p. 100).

A centralidade dos escritos Arendtiano remete-se ao indivíduo como um fim em si mesmo, de forma que a política não se constitui em corpo estatal ou em instituições. Essas, por sua vez, assumem aqui uma função estática e não ativa no processo de garantia dos direitos humanos. Mas como se verá na próxima seção, a universalidade desses direitos pode desencadear um processo sustentável de promoção do espaço público. Quando se considera a deficiência estatal em garantir esse fim, as organizações internacionais podem contribuir para a observância deste processo, fundamentadas na universalidade dos direitos humanos. Essa situação valoriza a atuação top down em contraposição ao argumento arendtiano do direito que nasce com a ação no espaço público. Não obstante, essa perspectiva apresentada por Arendt pode surtir efeito inverso ao cristalizar as desigualdades que ocorrem no espaço privado, antes mesmo da inserção do individuo na esfera pública. É o que ocorre com a diferença de gênero, objeto de discussão a seguir. Ademais, neste caso, é a atuação top down que permite promover o right to have rights ao contrário da construção botton up dos direitos.

2 Tradução livre da autora. No original: [...] reify structures of governance into rigid hierarchies with elites who remove individuals from potential sites of political action. 


\section{Promovendo o espaço público}

Esta seção busca ilustrar os contributos que podem decorrer da universalidade dos direitos humanos, enquanto instrumento que respalda a interferência dos organismos internacionais no plano doméstico. Nesse sentido, utiliza-se como estudo de caso para guiar a construção dessa argumentação, uma específica decisão da Comissão Interamericano de Direitos Humanos (CIDH) que condenou o Estado brasileiro por omissão em caso de violência contra a mulher, ferindo, desta forma, a declaração dos direitos humanos que suporta a atuação da Organização.

\subsection{Do espaço privado ao público: a trajetória da mulher brasileira}

Homens e Mulheres, ainda que estejam revestidos de igualdade formal pela Constituição Federal brasileira de 1988, disputam os espaços portando condições diferentes, sobretudo pelos valores atribuídos a cada um, situação esta que não se restringe apenas ao Estado brasileiro, mas que se traduz em um fenômeno alargado.

Nas palavras de Saffioti (2004, p. 35), as mulheres "são socializadas para desenvolver comportamentos dóceis, cordatos, apaziguadores. Os homens, ao contrário, são estimulados a desenvolver condutas agressivas, perigosas, que revela força e coragem.” Ao passo que esses papéis são representados na sociedade emerge um ideário de que a mulher é um ser frágil, dotada de habilidades que podem ser aproveitadas apenas em ambientes domésticos e privados, como o preparo da comida, a limpeza da casa e a assistência e acompanhamento dos filhos. A fixação dessa relação de gênero é fruto do processo de socialização que recai sobre cada indivíduo, etapa que lhe vai imprimir padrões comportamentais específicos aos ditames da sua cultura ou do corpo social, guiando-lhe de forma a reproduzir e perpetuar essas estruturas.

A instituição familiar é um exemplo da cristalização dessa estrutura pautada no patriarcado. Muito embora o atual Código Civil e Penal brasileiros apresentem o abandono de artigos que estipulavam a mulher, por exemplo, como relativamente capaz, dependendo do seu cônjuge para firmar acordos, e de criminosa, em caso de adultério, respectivamente, ainda a família continua a ser a instituição norteadora e garantidora de direitos que podem ser usufruídos pelas mulheres, ainda que sejam em prol da família. Nesse sentido, "[...] em vez de as mulheres serem investidas de direitos como sujeitos em si, elas somente são detentoras de direitos na medida em que estão ligadas ao ente família.", (BONETTI et al, 2009, p. 202)33.

Entretanto, as relações estruturadas a partir da lógica patriarcal, de dominação, quando contestada, ocorre, entre outros métodos, com o uso da violência cometida pelo mais forte. O produto da tentativa de libertação de tal ordem é o que se denomina de violência de gênero, sustentada pelo "conjunto das desigualdades sociais estruturais, que se expressam no marco do processo de produção e reprodução das relações fundamentais- as de classe, étnico-raciais e de gênero[...]" (ALMEIDA, 2007, p. 27). No Brasil, o resultado dessa ordem inventada traduz-se nos dados da pesquisa realizada pela Fundação Perseu Abramo, em outubro de 2001, revelando que:

A projeção da taxa de espancamento (11\%) para o universo investigado (61,5 milhões) indica que pelo menos $6,8 \%$, dentre as brasileiras vivas, já foram espancadas ao menos uma vez. Considera-se que entre as que admitiram terem sido espancadas, $31 \%$ declararam que a última vez que isso ocorreu foi no período dos 12 meses anteriores, projeta-se cerca de, no mínimo, 2,1 milhões de mulheres espancadas por ano no país (ou em 2001, pois não se sabe se estariam aumentando ou diminuindo), $175 \mathrm{mil} / \mathrm{mês}, 5,8 \mathrm{mil} / \mathrm{dia}, 243 /$ hora, $4 /$ minuto- uma a cada cinco segundos.

Todavia, a violência física que acomete as mulheres brasileiras "não se mantém sem a violência simbólica" (ALMEIDA, 2007, p. 29), o que Pierre Bourdieu entende por mecanismos diferentes de dominação. Nesse sentido, a violência sofrida dentro dos lares é apenas um prisma do fenômeno que compreende todas as esferas da sociedade, refletindo não apenas na esfera privada, mas também na esfera pública, que reduz a atuação feminina em número, aos serviços que se referem ao cuidado e a cargos que não envolvem a tomada de decisões.

\subsection{A Comissão Interamericana de Direitos Huma- nos e os contributos para o espaço público bra- sileiro.}

Considerando, portanto, que a violência contra a mulher é produto de um sistema de dominação que envolve indiscutivelmente a disputa pelo poder, sua incidência remete-se à "necesidad de control sobre el cuerpol la sexualidad y las emociones de las mujeres" (AGUADO, 2005, p. 27) e, contra essa prática, movimentos sociais e feministas passaram a intervir nessa ordem em busca de

3 Entendimento das autoras sobre o título VIII, capítulo VII "Da família, do adolescente e do idoso", da Constituição Federal brasileira. 
mudanças. Dessa forma, foi a partir da década de 1980, que os movimentos de mulheres passaram a contestar e a demandar a elaboração de políticas públicas mais eficazes para a promoção da igualdade entre homens e mulheres (BANDEIRA; BITTENCOURT, 2005). A violência contra a mulher também tornou-se pauta no plano nacional.

No plano internacional, elaborou-se a Convenção sobre a Eliminação de Todas as Formas de Discriminação Contra a Mulher (1979) ${ }^{4}$, considerada um instrumento imprescindível e norteador das ações estatais. A Convenção, além de reconhecer a desigualdade de gênero, induz os Estados signatários a criarem mecanismos para reverter essa situação, ao passo que redefine o próprio conceito de cidadania e do espaço político-social, consagrando o nascimento de novos atores políticos e desencadeando as transformações sociais e desestrutura a ordem hierárquica estabelecida entre os sexos (ÁVILA, 2002; PITANGUY, 2002).

Concomitantemente à evolução dos instrumentos internacionais de proteção às mulheres, observa-se no Brasil, no final do regime militar, início da década de oitenta, a expansão dos movimentos de mulheres pelo país de forma articulada para denunciar a violência cometida contra elas, não apenas nos espaços públicos, mas principalmente àquela praticada dentro dos lares (Bandeira, 2009). Nesse contexto, onde os movimentos feministas e grupos organizados buscam a emancipação da condição reduzida da mulher, tem-se a denúncia interposta à CIDH, em 1998, pela vítima Maria da Penha Maia Fernandes e duas outras instituições, contra o Estado brasileiro, por omissão deste face às agressões sofridas pela proponente e a ausência de sentença condenatória definitiva contra o agressor (seu ex-marido), que, à data da petição, completava 15 anos de tramitação do processo. Os proponentes da ação argüiram que este tipo de situação não representa um caso isolado no Brasil, onde a violência contra a mulher é sinônimo de impunidade, tendo em

4 A Convenção sobre a Eliminação de Todas as Formas de Violência contra a Mulher é o segundo tratado que mais obteve adesão dos Estados-Partes, perdendo apenas para a Convenção sobre os Direitos da Criança. No entanto, é o instrumento internacional de proteção que mais recebeu reservas dos países signatários. (LAVORENTI, 2009). Até novembro de 2006, 185 países já haviam aderido à Convenção. Vale lembrar que a CSW criou um protocolo facultativo à Convenção, o Comitê sobre a Eliminação da Discriminação contra a Mulher, Comitê CEDAW, com vistas a monitorar a implementação da Convenção nos Estados-Partes (PIMENTEL, 2008). vista as poucas denunciais que se convertem em processo e recebem uma sentença (COMISSÃO INTERAMERICANA DE DIREITOS HUMANOS, 2000)

A Comissão Interamericana de Direitos Humanos $(\mathrm{CIDH})$, juntamente com a Corte Interamericana de Direitos Humanos (SIDH), compõe o Sistema Interamericano de Direitos Humanos (SIDH) ${ }^{5}$. A CIDH tem por prerrogativa, entre outras, inspecionar a situação dos direitos humanos nos Estados Partes ${ }^{6}$ e emitir relatórios; estabelecer o diálogo com diversos segmentos da sociedade; editar medidas para garantir maior independência do sistema judiciário doméstico, os direitos humanos das mulheres, dos menores e dos povos indígenas; e receber, analisar e julgar petições individuais que reclamam a violação de DH.7 Os países signatários da Convenção comprometem-se, desta forma, a observá-la e a fazer valer o corpo do seu texto nas suas esferas de domínio, e atribuem ao SIDH a missão de avaliar a sua implementação.

Em virtude dessas prerrogativas, a $\mathrm{CIDH}$ condenou o Estado brasileiro pela omissão do seu sistema judiciário face às reiteradas denúncias de violência doméstica cometida contra a autora da ação. O país foi condenado a proceder com o julgamento do agressor e a elaborar uma lei específica para coibir a violência contra a mulher, além de outras recomendações (BRASIL, 2011).

Dando cumprimento à sentença, o Brasil em Agosto de 2006 promulgou a lei 11.340, cunhada de lei Maria da Penha, que “incorporou o avanço legislativo internacional e se transformou no principal instrumento legal de enfrentamento à violência doméstica contra a mulher no Brasil” (BRASIL, 2011). A condenação do Brasil desencadeou um alargado debate interno que contribuiu não apenas para a elaboração de políticas públicas mais eficazes para o combate à violência, como suscitou questões importantes acerca do tema ${ }^{8}$. Não obstante,

5 A SIDH é resultado da Declaração Americana dos Direitos e Deveres do Homem (1948) e da Convenção sobre Direitos Humanos (1969).

6 Até o momento foram elaborados 44 relatórios referentes às visitas realizadas em 23 Estados Americanos

7 Os Estados Americanos que ratificaram a Convenção e que estão sujeitos ao seu cumprimento somam 24: Argentina, Barbados, Bolívia, Brasil, Colômbia, Costa Rica, Chile, Dominica, Equador, El Salvador, Grenada, Guatemala, Haiti, Honduras, Jamaica, México, Nicarágua, Panamá, Paraguai, Peru, República Dominicana, Suriname, Uruguai e Venezuela.

8 Aproximadamente 200 mil mulheres brasileiras participaram de conferências municipais, estaduais e nacional, juntamente 
cumpre ressaltar que a condenação brasileira fortaleceu ainda mais o discurso dos movimentos sociais e feministas que lutavam pelos direitos das mulheres.

Dessa forma, as transformações que ocorreram no Brasil em benefício das mulheres é conseqüência, sobretudo, da responsabilidade que o país compartilha com a comunidade internacional em relação à promoção dos direitos humanos, que neste caso é compatível com os princípios da sua Constituição Federal. Entretanto, foi a decisão externa, da CIDH, obrigando-o ao cumprimento de determinadas medidas, o fator determinante e impulsionador das ações adotadas pelo país, sobre esta temática.

Nesse sentido, a insuficiência do Estado brasileiro em prover os direitos dos seus internos, neste exemplo os direitos das mulheres, permitiu a interferência de um organismo internacional com o objetivo de pressionar o país a cumprir a Convenção dos Direitos do Homem e de Eliminação da Discriminação contra a Mulher. Este exemplo ilustra como os direitos humanos, que tem em seu fundamento a universalidade, podem representar um importante mecanismo para a abertura do espaço público.

Ainda que a condenação tenha se voltado ao fenômeno da violência contra a mulher, os efeitos advindos do seu enfrentamento abrangem todos os campos, porque se o contrato original é estabelecido entre homens em torno do objeto mulher, a diferença sexual que nele se estabelece, converte-se em diferença política e, por conseguinte, transforma o "pessoal em público" (SAFFIOTI, 2004, p. 55). Assim, o combate à violência de gênero envolve, sobretudo, a conscientização sobre as relações estruturadas a partir das diferenças entre os sexos e o emponderamento das mulheres vítimas.

Arendt acreditava que os direitos do homem são garantidos pela comunidade política que o representa, reflexo da sua cultura e valores e, nesse sentido, direitos humanos estabelecidos como valores universais poderiam escamotear o processo político local. Mas como ilustrado acima, ainda que os valores sejam universais, sendo eles compatíveis com os princípios norteadores da ação do país que o adota, organismos externos podem colaborar para a

com representantes de vários ministérios e Presidência da República, com o objetivo de apresentar demandas e contribuir para a construção do II Plano Nacional de Políticas para as Mulheres, que compreende ações voltadas ao combate à violência, à inclusão das mulheres no mundo do trabalho e nos espaços de poder e decisão, ao direito à terra, ao desenvolvimento sustentável, entre outros (II PNPM, 2008). promoção de um espaço público interno mais participativo, em situações que o Estado não é suficientemente capaz de assegurar a participação dos indivíduos nesse espaço e, ao mesmo tempo, de assegurar os direitos humanos.

Como demonstrado acima, a sociedade brasileira ainda apresenta um elevado grau de discriminação contra a mulher, a qual toma a forma extremada de violência e também reflete na participação feminina no espaço público. Por conseguinte, supor que o princípio inerente a toda a condição humana (right to have rights) é a possibilidade de agir no espaço público, demonstra-se demasiado limitado e não menos problemático que os direitos humanos, tendo em vista que a constituição das sociedades baseia-se em valores que têm em si imbuído a desigualdade.

A preocupação de Arendt era garantir a ligação dos indivíduos a uma comunidade. Contudo, estar inserido em alguma comunidade não é sinônimo de participar do espaço público portando os mesmos direitos, como ilustrado anteriormente. Por sua vez, a divisão entre espaço público e privado, assim como a necessidade da sua proteção, pode contribuir para inserção assimétrica dos indivíduos no espaço público. No caso das mulheres, ao se transferir sistematicamente o seu poder aos homens, estes garantem a sua liberdade, a sua auto-realização, e mantêm o seu status, revelando dois aspectos dessa exploração de gênero: a transferência do labor material ao homem, bem como a sua nutrição por meio do sexo (YOUNG, 1990, p. 51).

Nesse sentido, a possibilidade de interferência de um organismo internacional no espaço doméstico, consubstanciado nos direitos humanos, pode apresentar contributos inefáveis no sentido de promover espaço público interno, assegurando um processo de construção de políticas que engloba diferentes agentes. No mesmo sentido, right to have rights, proposto por Arendt, só alcança o seu pressuposto se considerar os contributos de uma ação top down, praticada não pelo Estado, mas por agentes externos à sua fronteira.

\section{Conclusão}

O presente trabalho buscou evidenciar as limitações do pensamento arendtiano no que concerne ao right to have rights. Ao advogar por um princípio que seja inerente a toda a condição humana com o objetivo de embasar o direito do ser humano, a autora desconsidera a possibilidade da sua garantia ocorrer por meio dos 
direitos humanos. Seus fundamentos repousam, segundo Arendt, na abstração e universalidade, de forma que não refletem os valores e necessidades locais, não obstante a sua implementação e observação estarem condicionadas por alguma instituição.

Muito embora essa crítica suscite questões importantes, a ação, enquanto princípio que perpassa a existência humana, não afasta os problemas dos direitos humanos, porque a possibilidade de agir no espaço público não é garantia suficiente de inserção igualitária nessa esfera e a situação das mulheres brasileiras é um importante exemplo que ilustra essa insuficiência.

Ainda assim, Arendt evidencia o espaço público como um campo em que os indivíduos, livres, atuam em concerto para debater e construir. No caso do Brasil, a ação em concerto só tem sido possível, em parte, em decorrência de uma decisão externa que culpabilizou o Estado face à sua omissão em caso de violência contra a mulher e exigiu a adoção de medidas que visassem reverter a situação não só da vítima, mas também do fenômeno da violência no país.

A violência que incide sobre as mulheres pauta-se nos mesmos fundamentos que restringem a sua participação no espaço público, limitando-o, desta forma, à atuação dos homens, em decorrência, sobretudo, dos princípios que sustentam a organização social brasileira. Os efeitos decorrentes da desigualdade de gênero constrangem a mulher a atuar na esfera privada e dessa forma limita a idéia arendtiana do direito a partir da ação.

Dessa forma, a transformação iniciada na sociedade brasileira, a partir da decisão externa, busca modificar a relação estrutural que embasa a desigualdade de gênero, à medida que promove e resguarda a participação feminina na discussão e construção de políticas públicas destinadas a balizar as diferenças existentes entre ambos os sexos (II PNPM, 2008), contribuindo, por sua vez, para a promoção do espaço público nos termos arendtianos e igualmente para o fortalecimento das instituições que têm o dever de protegê-lo.

\section{Referências}

AGUADO, Ana. "Violência de gênero: sujeto femenino y ciudadanía em La sociedad contemporânea". In: OLIVEIRA, Suely; CASTILLO-MARTÍN, Márcia. Marcadas a ferro: violência contra a mulher, uma visão multidisciplinar. Brasília: SEPM, 2005.
ARENDT, Hannah. A vida do espírito. Lisboa: Instituto Piaget, 1978. v. 2.

ARENDT, Hannah. A condição humana. Lisboa: Relógio D’água, 2001.

ARENDT, Hannah. As origens do totalitarismo. Lisboa: Dom Quixote, 2004.

AVRITZER, Leonardo. Ação, Fundação e Autoridade em Hannah Arendt. Lua Nova, São Paulo, v. 68, p. 147-167, 2006.

ÁVILA, Maria Betânia. Cidadania, direitos humanos e direitos das mulheres. In: UNBEHUM, Sandra G.; Bruschini, Cristina (Org.). Gênero democracia e sociedade brasileira. São Paulo: editora 34, 2001

BANDEIRA, Lourdes; BITTENCOURT, Fernanda. Desafios da transversalidade de gênero nas políticas públicas brasileiras. In: SWAIN, Tania Navarro; MUNIZ, Diva Couto Gontijo Muniz. Mulheres em ação: práticas discursivas, práticas políticas. Florianópolis: Mulheres, 2005.

BANDEIRA, Lourdes. Três décadas de resistência feminista contra o sexismo e a violência feminina no Brasil: 1976 a 2006. Sociedade e Estado, Brasília, v. 24, n. 2, p. 401-438, maio/ago 2009.

BIRMINGHAIN, Peg. Hannah Arendt and Human Rights: the Predicament $\mathrm{f}$ Common Responsibility. Indianapolis: Indiana University Press, 2006.

BONETTI, Alinne et al. Sujeitos de direitos? Cidadania feminina nos vinte anos da constituição cidadã. Políticas Sociais: acompanhamento e análise, Brasília, v. 3, n. 17, p. 199-257, 2009.

BRASIL. Secretaria de políticas para as mulheres. Lei Maria da Penha. Disponível em: <http://www.sepm.gov. $\mathrm{br} /$ subsecretaria-de-enfrentamento-a-violencia-contraas-mulheres/lei-maria-da-penha/breve-historico $>$. Acesso em: 15 abr. 2011.

BRASIL. Secretaria Especial de Políticas Para as Mulheres. II Plano Nacional de Política para as Mulheres. Brasília: SPM, 2008. Disponível em: <http://bvsms.saude.gov.br/ bvs/publicacoes/II_PNPM.pdf>. Acesso em: 10 abr. 2011

COHEN, Jean L; ARATO, Andrew. Sociedad Civil y Teoría Política. La critica normativa: Hannah Arendt. México: Fondo de Cultura Económica, 2000.

COMISSÃO INTERAMERICANA DE DIREITOS HUMANOS. Convenção Interamericana para prevenir, punir e erradicar a violência contra a mulher: Convenção Belém do Pará. Disponível em: <http://www.cidh.org/ 
Basicos/Portugues/m.Belem.do.Para.htm.> Acesso em: 10 abr. 2011.

COMISSÃO INTERAMERICANA DE DIREITOS HUMANOS. Relatório Anual 2000 n 54/01. Caso 12.051. Maria Maia da Penha Fernandes. Disponível em: <http:// www.cidh.oas.org/annualrep/2000port/12051.htm >. Acesso em:11 abr. 2011.

COTTER, Bridget. Hannah Arendt and "The Right to have Rights. In: LANG, Anthony F e WILLIAMS, John. Hannah Arendt and international relations: reading across the lines. New York: Palgrave Macmillan, 2005. p. 95- 112 .

FRAZER, Elisabeth. Hannah Arendt: the risks of the public realm. Critical Review of International Social and Political Philosophy. United Kingdom: v.12, n. 2, p. 203223, 2009

FUNDAÇÃO PERSEU ABRAMO. Violência contra $a$ mulher. 2001. Disponível em: <http://www.especiais.com. br/pesquisa_abramo.pdf $>$. Acesso em:14 abr. 2011.

LANG, Anthony F; WILLIAMS, John (Ed.). Hannah Arendt and international relations: reading across the lines. New York: Palgrave Macmillan. 2005. p.1-26.

LANG, Anthony F. Governance and political action: Hannah Arendt on global political protest in lang. In: ANTHONY F.; WILLIAMS, John (Ed.). Hannah Arendt and international relations: reading across the lines. New York: Palgrave Macmillan, 2005.p. 179- 198.

LAVORENTI, Wilson. Violência e discriminação contra a mulher: tratados internacionais de proteção de proteção e o direito penal brasileiro. Campinas: Millennium, 2009.
LEE, Christopher. Locating Hannah Arendt within Postcolonial fought: a prospectus. West Chester, Pennsylvania, USA: College Literature, v. 38, n.1, p95-114, 2011.

OMAN, Natalia. "Hannah Arendt's "Right to Have Rights": a philosophical context for human security. Connecticut, USA: Journal of Human Rights, v.9, n.3, p. 279-302, 2010.

OWENS, Patricia. Between war and politics: international relations and the thought of Hannah Arendt. Oxford: Oxford University Press, 2009.

PAREKH, Serena. A meaningful place in the world: Hannah Arendt on the nature of human rights. Connecticut, USA: Journal of Human Rights, v. 3, n. 1, p. 41-53, 2004.

PITANGUY, Jacqueline. Gênero, cidadania e direitos humanos. In: UNBEHUM, Sandra G.; BRUSCHINI, Cristina (Org.). Gênero democracia e sociedade brasileira. São Paulo: Editora 34, 2002.

PIMENTEL, Silvia. Comitê CEDAW: experiências e desafios. Brasília: SPM, 2008.

SAFFIOTI, Heleieth I. B. Gênero, patriarcado, violência. São Paulo: Fundação Perseu Abramo, 2004.

WILLIAMS. John. Hannah Arendt and the international space in-between? In: LANG, Anthony F; WILLIAMS, John (Ed.) Hannah Arendt and international relations: reading across the lines. New York: Palgrave Macmillan, 2005. p. 199-221.

YOUNG, Iris Marion. Justice and the Politics of difference. New Jersey: Princeton University Press, 1990. 